\title{
Integrated disease mapping in a polyparasitic world
}

\author{
Simon Brooker ${ }^{1}$, Jürg Utzinger ${ }^{2}$ \\ ${ }^{1}$ Department of Infectious and Tropical Diseases, London School of Hygiene and Tropical Medicine, \\ Keppel Street, London WC1E 7HT, United Kingdom; ${ }^{2}$ Department of Public Health and Epidemiology, \\ Swiss Tropical Institute, P.O. Box, CH-4002 Basel, Switzerland
}

Keywords: geostatistics, geographical information system, integrated control, malaria, neglected tropical diseases, polyparasitism, remote sensing, risk mapping and prediction.

\section{Malaria and the neglected tropical diseases}

In the past, and still today, people living in the developing world have been, and continue to be, repeatedly exposed to a number of endemic parasitic diseases which impose an intolerable economic, health and social burden on their societies (Stoll, 1947; Sachs and Malaney, 2002). Among the parasitic diseases, malaria due to Plasmodium falciparum inflicts the largest burden (Snow et al., 2005). Concurrently, hundreds of millions of people are plagued by a number of so-called neglected tropical diseases (NTDs). The most significant of these are Chagas disease in South America, human African trypanosomiasis, leishmaniasis, lymphatic filariasis, onchocerciasis, schistosomiasis, soil-transmitted helminthiasis and trachoma. The scale of the problem is illustrated in Table 1, which summarises current population statistics, including at-risk populations, estimated numbers of people infected, annual morbidity and mortality rates and burden estimates due to malaria and the above-mentioned NTDs.

In recent years, there has been an upsurge in public and private spending in global health, with par-

\footnotetext{
Corresponding author:

Simon Brooker

Department of Infectious and Tropical Diseases

London School of Hygiene and Tropical Medicine

Keppel Street, London WC1E 7HT, United Kingdom

Tel. + 44207927 2614; Fax + 442079272918

E-mail: simon.brooker@lshtm.ac.uk
}

ticular efforts aimed at tackling HIV/AIDS, tuberculosis and malaria (Lu et al., 2006). With enhanced funding coming on stream also for the NTDs, new partnerships and global alliances have been formed to tackle a number of NTDs, with preventive chemotherapy playing a key role (Brady et al., 2006; Hotez et al., 2006; WHO, 2006). This funding has coincided with calls to improve the coordination and integration of national control programmes, placing emphasis on simultaneous morbidity control due to NTDs (e.g. schistosomiasis and soil-transmitted helminthiasis) or to eliminate NTDs as a publichealth problem (e.g. lymphatic filariasis) (Brady et al., 2006; Lammie et al., 2006). To help allocate public-health resources, an essential first step is to delineate and understand the spatial distribution of different parasitic diseases (Brooker et al., 2006; Hay and Snow, 2006; Utzinger and de Savigny, 2006).

\section{Mapping and prediction of co-endemic areas}

The need

Parasite transmission intensity exhibits significant spatial and temporal heterogeneity and, because of their neglected nature, there exists limited information about the exact geographical distribution of most of the NTDs, as well as malaria (Polack et al., 2005; Hay and Snow, 2006). It follows that the spatial congruence of different NTDs, as well as of 
Table 1. Current global estimates of populations at risk, number of people infected and suffering from morbidity, and annual mortality rates and burden estimates of malaria and selected NTDs (DALY, disability-adjusted life year; NA, not applicable; ND, not determined). The DALY is a summary measure of disease burden that combines the impact of illness, disability and mortality on population health and was last estimated by the World Health Organization in 2002 (http://www.who.int/healthinfo/bod/en/index.html).

\begin{tabular}{|c|c|c|c|c|c|c|c|}
\hline Disease & Causative agent(s) & $\begin{array}{l}\text { Population } \\
\text { at risk } \\
\left(\mathrm{x} 10^{6}\right) \\
\end{array}$ & $\begin{array}{c}\text { People } \\
\text { infected } \\
\left(\mathrm{x} 10^{6}\right) \\
\end{array}$ & $\begin{array}{l}\text { Morbidity } \\
\left(\mathrm{x} 10^{6}\right)\end{array}$ & $\begin{array}{l}\text { Mortality } \\
\left(\mathrm{x} 10^{3}\right)\end{array}$ & $\begin{array}{c}\text { Burden } \\
\text { (x 10 DALYs) }\end{array}$ & Reference \\
\hline Malaria & $\begin{array}{l}\text { Plasmodium falciparum, } \\
\text { P. malariae, P. ovale, } \\
\text { P. vivax }\end{array}$ & 2211 & NA & 515 & 1272 & 46.49 & $\begin{array}{l}\text { WHO, 2004; } \\
\text { Snow et al., } \\
2005\end{array}$ \\
\hline \multicolumn{8}{|l|}{$\begin{array}{l}\text { Soil-transmitted } \\
\text { helminthiasis }\end{array}$} \\
\hline Ascariasis & Ascaris lumbricoides & 4211 & $807-1221$ & 350 & $3-60$ & $1.82-10.5$ & $\begin{array}{l}\text { Bethony et al., } \\
\text { 2006; Lammie } \\
\text { et al., } 2006\end{array}$ \\
\hline $\begin{array}{l}\text { Hookworm } \\
\text { disease }\end{array}$ & $\begin{array}{l}\text { Ancylostoma duodenale, } \\
\text { Necator americanus }\end{array}$ & 3195 & $576-740$ & 150 & $3-65$ & $0.06-22.1$ & $\begin{array}{l}\text { Bethony et al., } \\
\text { 2006; Lammie } \\
\text { et al., } 2006\end{array}$ \\
\hline Trichuriasis & Trichuris trichiura & 3212 & $604-795$ & 220 & $3-10$ & $1.01-6.4$ & $\begin{array}{l}\text { Bethony et al., } \\
\text { 2006; Lammie } \\
\text { et al., } 2006\end{array}$ \\
\hline Strongyloidiasis & Strongyloides stercoralis & ND & $30-100$ & ND & ND & ND & $\begin{array}{l}\text { Bethony et al., } \\
2006\end{array}$ \\
\hline $\begin{array}{l}\text { Lymphatic } \\
\text { filariasis }\end{array}$ & $\begin{array}{l}\text { Wuchereria bancrofti, } \\
\text { Brugia malayi, B. timori }\end{array}$ & $>1000$ & 120 & 43 & 0 & 5.78 & $\begin{array}{l}\text { Lammie et al., } \\
2006\end{array}$ \\
\hline Schistosomiasis & $\begin{array}{l}\text { Schistosoma haematobium, } \\
\text { S. intercalatum, } \\
\text { S. japonicum, S. mansoni, } \\
\text { S. mekongi }\end{array}$ & 779 & 207 & 120 & $15-280$ & $1.7-4.5$ & $\begin{array}{l}\text { Lammie et al., } \\
2006\end{array}$ \\
\hline Trachoma & Chlamydia trachomatis & ND & 150 & ND & 0 & 2.33 & WHO, 2004 \\
\hline Onchocerciasis & Onchocerca volvulus & 120 & 18 & ND & 0 & 0.48 & $\begin{array}{l}\text { Watkins, 2003; } \\
\text { WHO, } 2004\end{array}$ \\
\hline Leishmaniasis & $\begin{array}{l}\text { Leishmania donovani, } \\
\text { L. chagasi, L. infantum }\end{array}$ & 350 & 12 & ND & 51 & 2.09 & $\begin{array}{l}\text { Watkins, 2003; } \\
\text { WHO, 2004 }\end{array}$ \\
\hline $\begin{array}{l}\text { Human African } \\
\text { trypasosomiasis }\end{array}$ & $\begin{array}{l}\text { Trypanosoma brucei } \\
\text { gambiense, } \\
\text { T. b. rhodesiense }\end{array}$ & $>60$ & 0.5 & ND & 50 & 1.53 & $\begin{array}{l}\text { Watkins, 2003; } \\
\text { WHO, } 2004\end{array}$ \\
\hline Chagas disease & Trypanosoma cruzi & 120 & $11-18$ & ND & 13 & 0.67 & $\begin{array}{l}\text { Watkins, 2003; } \\
\text { WHO, } 2004\end{array}$ \\
\hline
\end{tabular}


NTDs and $P$. falciparum malaria, remains poorly defined. On the other hand, significant progress has been made with a number of geospatial tools, such as geographical information systems (GIS), remotely-sensed environmental data, and geostatistics that allow to better describe, understand and predict the geographical distribution of single NTDs (Malone, 2005; Yang et al., 2005; Brooker, 2007). Ultimately, these geospatial tools offer the potential to improve the spatio-temporal targeting of control measures and to enhance the cost-effectiveness of integrated disease control programmes.

\section{The proposal}

In the context of integrated disease control, we propose that the spatial co-distribution of different parasite species over large geographical areas, such as at continental scales, can be based initially on climate-based disease risk maps (Brooker et al., 2006). Such maps, however, belie the geographical variation of co-distribution and co-infection evident at community and district levels, which is difficult to capture with existing risk models. To date, only one study has attempted to analyse the spatial occurrence of co-infection at a small spatial scale (an area of $40 \times 60 \mathrm{~km}$ ) within a single district of a West African country (Raso et al., 2006). This study showed that it was possible to predict spatial patterns of Schistosoma mansoni-hookworm co-infec- tions. Future similar work for different parasite species in varying transmission settings, coupled with an improved understanding of spatial risk factors of different parasite species will allow the projection of co-endemicity on the basis of remotelysensed satellite data, as well as behavioural, demographic, epidemiological and socio-economic risk factors. Such research will aid the development of risk maps which can identify large-scale patterns of potential overlap, and thus guide regional and national level integrated disease control efforts.

At finer scales, on the other hand, there remains a need to undertake rapid and inexpensive assessments of infection levels to guide local control. Table 2 summarises different approaches that have been developed and successfully validated for the rapid assessment of different NTDs. For example, a simple morbidity questionnaire administered through the existing education system allows the rapid delineation of high-risk areas of schistosomiasis haematobia, based on the specific symptomatology of Schistosoma haematobium, which is the presence of blood in urine (Lengeler et al., 2002). With regard to lymphatic filariasis, onchocerciasis and visceral leishmaniasis, accurate, non-invasive, rapid antigen detection assays applicable under field conditions have become available (Weil et al., 1997; Ayong et al., 2005; Chappuis et al., 2006). In the case of lymphatic filariasis, mapping of disease distributions has been based on the use immunochro-

Table 2. Tools currently available for rapid and inexpensive assessment of high-risk communities, and hence for mapping purposes, of a number of NTDs.

\begin{tabular}{llll}
\hline Disease & Causative agent(s) & Rapid assessment approach & Reference \\
\hline Schistosomiasis & Schistosoma haematobium & Morbidity questionnaires: reported blood in urine & Lengeler et al., 2002 \\
& Schistosoma mansoni & Morbidity questionnaires: reported blood in stool & Lengeler et al., 2002 \\
& & Close proximity to lakes $(<5 \mathrm{~km})$ & Lengeler et al., 2002 \\
& Schistosoma japonicum & Morbidity questionnaires: reported blood in stool & Zhou et al., 1998 \\
Lymphatic filariasis & Wuchereria bancrofti & Antigen detection assay: ICT & Weil et al., 1997 \\
& & Lot quality assurance sampling & Vanamail et al., 2006 \\
Leishmaniasis & $\begin{array}{l}\text { Leishmania donovani, } \\
\text { L. chagasi, L. infantum } \\
\text { Onchocerca volvulus }\end{array}$ & Antigen detection assay: K39 strip test & Chappuis et al., 2006 \\
Onchocerciasis & & & Antigen detection assay: Oncho-dipstick test
\end{tabular}


matographic card tests (ICT) for the detection of circulating antigen from adult Wuchereria bancrofti filarial antigenaemia in order to target mass drug administration (Gyapong et al., 2002).

Recent operational research has also highlighted the potential of lot quality assurance sampling of a small number of individuals attending primary schools for identifying high-risk communities for schistosomiasis mansoni (Brooker et al., 2005) and for monitoring lymphatic filariasis control programmes (Vanamail et al., 2006). Further investigation and comparison of the cost-effectiveness of different rapid mapping approaches, used singly or in combination, is clearly warranted. We conjecture that it should be possible to integrate the rapid mapping of different NTDs simultaneously with tools that are already available, and that this is an area which merits investigation.

\section{Challenges and opportunities}

A major challenge for such geospatial research will be to integrate the disease-specific ecologies and epidemiologies of different parasite species and vector/intermediate host species, as well as contextual determinants (e.g. behaviour, density and migration patterns of humans and socio-economic status) into a single analytical framework. For example, recent studies have highlighted intrinsic differences in the spatial heterogeneity of specific diseases depending on the eco-epidemiological and socio-cultural setting (Gyapong et al., 2002; Brooker et al., 2004). Hence, understanding the complexity of risk factors of co-distribution and co-infection require detailed field studies, including validation of generated risk maps of co-infections. The studies will also necessitate the development of new geostatistical methods, building on the successful application of Bayesian geostatistical approaches in modelling spatial distributions of single parasite species (Gemperli et al., 2004; Raso et al., 2005; Clements et al., 2006).

Finally, the development of an integrated approach to map and predict a number of different NTDs simultaneously would require careful consid- eration of the different spatial heterogeneities of different species and over what spatial scale variation occurs, as well as simulation studies to determine the optimal sample size to capture species-specific epidemiological patterns.

\section{Concluding remarks}

As public-health resources are increasingly available to address global health issues as part of unprecedented efforts to meet international development goals, large-scale control efforts get underway, most recently also to tackle NTDs. The initiation of such control does not, however, signal the end of geospatial research rather underscores its vital importance. Numerous geospatial issues require attention, including geostatistical techniques that should go hand-in-hand with field studies and operational research, thus requiring collaboration among geospatial scientists and public-health specialists. Such work will determine whether research can have a real public-health impact rather than remain only an academic exercise.

\section{Acknowledgements}

Simon Brooker is supported by a Wellcome Trust Advanced Training Fellowship (073656) and Jürg Utzinger is grateful to the Swiss National Science Foundation for financial support (project no. PPOOB-102883).

\section{References}

Ayong LS, Tume CB, Wembe FE, Simo G, Asonganyi T, Lando G, Ngu JL, 2005. Development and evaluation of an antigen detection dipstick assay for the diagnosis of human onchocerciasis. Trop Med Int Health 10, 228-233.

Bethony J, Brooker S, Albonico M, Geiger SM, Loukas A, Diemert D, Hotez PJ, 2006. Soil-transmitted helminth infections: ascariasis, trichuriasis, and hookworm. Lancet 367, 1521-1532. 
Brady MA, Hooper PJ, Ottesen EA, 2006. Projected benefits from integrating NTD programs in sub-Saharan Africa. Trends Parasitol 22, 285-291.

Brooker S, 2007. Spatial epidemiology of human schistosomiasis in Africa: risk models, transmission dynamics and control. Trans R Soc Trop Med Hyg 101, 1-8.

Brooker S, Clements ACA, Hotez PJ, Hay SI, Tatem AJ, Bundy DAP, Snow RW, 2006. The co-distribution of Plasmodium falciparum and hookworm among African schoolchildren. Malar J 5, 99.

Brooker S, Kabatereine NB, Myatt M, Stothard JR, Fenwick A, 2005. Rapid assessment of Schistosoma mansoni: the validity, applicability and cost-effectiveness of the lot quality assurance sampling method in Uganda. Trop Med Int Health 10, 647-658.

Brooker S, Kabatereine NB, Tukahebwa EM, Kazibwe F, 2004. Spatial analysis of the distribution of intestinal nematode infections in Uganda. Epidemiol Infect 132, 1065-1071.

Chappuis F, Rijal S, Soto A, Menten J, Boelaert M, 2006. A meta-analysis of the diagnostic performance of the direct agglutination test and rK39 dipstick for visceral leishmaniasis. BMJ 333, 723.

Clements ACA, Moyeed R, Brooker S, 2006. Bayesian geostatistical prediction of the intensity of infection with Schistosoma mansoni in East Africa. Parasitology 133, 711-719.

Gemperli A, Vounatsou P, Kleinschmidt I, Bagayoko M, Lengeler C, Smith T, 2004. Spatial patterns of infant mortality in Mali: the effect of malaria endemicity. Am J Epidemiol 159, 64-72.

Gyapong JO, Kyelem D, Kleinschmidt I, Agbo K, Ahouandogbo F, Gaba J, Owusu-Banahene G, Sanou S, Sodahlon YK, Biswas G, Kale OO, Molyneux DH, Roungou JB, Thomson MC, Remme J, 2002. The use of spatial analysis in mapping the distribution of bancroftian filariasis in four West African countries. Ann Trop Med Parasitol 96, 695-705.

Hay SI, Snow RW, 2006. The malaria atlas project: developing global maps of malaria risk. PLoS Med 3, e473.

Hotez PJ, Molyneux DH, Fenwick A, Ottesen E, Ehrlich Sachs S, Sachs JD, 2006. Incorporating a rapid-impact package for neglected tropical diseases with programs for HIV/AIDS, tuberculosis, and malaria. PLoS Med 3, e102.

Lammie PJ, Fenwick A, Utzinger J, 2006. A blueprint for suc- cess: integration of neglected tropical disease control programmes. Trends Parasitol 22, 313-321.

Lengeler C, Utzinger J, Tanner M, 2002. Questionnaires for rapid screening of schistosomiasis in sub-Saharan Africa. Bull World Health Organ 80, 235-242.

Lu CL, Michaud CM, Khan K, Murray CJL, 2006. Absorptive capacity and disbursements by the Global Fund to Fight AIDS, Tuberculosis and Malaria: analysis of grant implementation. Lancet 368, 483-488.

Malone JB, 2005. Biology-based mapping of vector-borne parasites by geographic information systems and remote sensing. Parassitologia 47, 27-50.

Polack S, Brooker S, Kuper H, Mariotti S, Mabey D, Foster A, 2005. Mapping the global distribution of trachoma. Bull World Health Organ 83, 913-919.

Raso G, Matthys B, N'Goran EK, Tanner M, Vounatsou P, Utzinger J, 2005. Spatial risk prediction and mapping of Schistosoma mansoni infections among schoolchildren living in western Côte d'Ivoire. Parasitology 131, 97-108.

Raso G, Vounatsou P, Singer BH, N'Goran EK, Tanner M, Utzinger J, 2006. An integrated approach for risk profiling and spatial prediction of Schistosoma mansoni-hookworm coinfection. Proc Natl Acad Sci USA 103, 6934-6939.

Sachs J, Malaney P, 2002. The economic and social burden of malaria. Nature 415, 680-685.

Snow RW, Guerra CA, Noor AM, Myint HY, Hay SI, 2005. The global distribution of clinical episodes of Plasmodium falciparum malaria. Nature 434, 214-217.

Stoll NR, 1947. This wormy world. J Parasitol. 33, 1-18.

Utzinger J, de Savigny D, 2006. Control of neglected tropical diseases: integrated chemotherapy and beyond. PLoS Med 3, e112.

Vanamail P, Subramanian S, Srividya A, Ravi R, Krishnamoorthy K, Das PK, 2006. Operational feasibility of lot quality assurance sampling (LQAS) as a tool in routine process monitoring of filariasis control programmes. Trop Med Int Health 11, 1256-1263.

Watkins BM, 2003. Drugs for the control of parasitic diseases: current status and development. Trends Parasitol 19, 477-478.

Weil GJ, Lammie PJ, Weiss N, 1997. The ICT filariasis test: a rapid-format antigen test for diagnosis of bancroftian filariasis. Parasitol Today 13, 401-404.

WHO, 2004. The world health report 2004: changing history. 
World Health Organization, Geneva.

WHO, 2006. Preventive chemotherapy in human helminthiasis. Coordinated use of anthelmintihic drugs in control interventions: a manual for health professionals and programme managers. World Health Organization, Geneva.

Yang GJ, Vounatsou P, Zhou XN, Utzinger J, Tanner M, 2005. A review of geographic information system and remote sensing with applications to the epidemiology and control of schistosomiasis in China. Acta Trop 96, 117-129. Zhou H, Ross AGP, Hartel GF, Sleigh AC, Williams GM, McManus DP, Luo XS, He Y, Li YS, 1998. Diagnosis of schistosomiasis japonica in Chinese schoolchildren by administration of a questionnaire. Trans R Soc Trop Med Hyg 92, 245-250. 